\title{
Corticosteroids for hospitalized patients with mild to critically-ill COVID-19: A multicenter, retrospective, propensity score-matched study
}

Satoshi Ikeda ( $\square$ isatoshi0112@gmail.com)

Kanagawa Cardiovascular and Respiratory Center https://orcid.org/0000-0001-5203-7911

Toshihiro Misumi

Yokohama City University School of Medicine

Shinyu Izumi

National Center for Global Health and Medicine

Keita Sakamoto

National Center for Global Health and Medicine

Naoki Nishimura

St. Luke's International Hospital

Shosei Ro

St. Luke's International Hospital

Koichi Fukunaga

Keio University School of Medicine

Satoshi Okamori

Keio University School of Medicine

Natsuo Tachikawa

Yokohama Municipal Citizen's Hospital

Nobuyuki Miyata

Yokohama Municipal Citizen's Hospital

Masaharu Shinkai

Tokyo Shinagawa Hospital

Masahiro Shinoda

Tokyo Shinagawa Hospital

Yasunari Miyazaki

Tokyo Medical \& Dental University

Yuki lijima

Tokyo Medical \& Dental University

Takehiro Izumo

Japanese Red Cross Medical Center

Minoru Inomata

Japanese Red Cross Medical Center

Masaki Okamoto

National Hospital Organization Kyushu Medical Center

Tomoyoshi Yamaguchi

Tokyo Rinkai Hospital

Keisuke Iwabuchi

Kanagawa Prefectural Ashigarakami Hospital

\section{Makoto Masuda}

Fujisawa City Hospital

Hiroyuki Takoi

Tokyo Medical University

Yoshitaka Oyamada

National Hospital Organization Tokyo Medical Center

Shigeki Fujitani

St Marianna University School of Medicine

Masamichi Mineshita

St Marianna University School of Medicine

Haruyuki Ishii

Kyorin University School of Medicine

Atsushi Nakagawa 
Kobe City Hospital Organization Kobe City Medical Center General Hospital

Nobuhiro Yamaguchi

Yokosuka City Hospital

Makoto Hibino

Shonan Fujisawa Tokushukai Hospital

Kenji Tsushima

International University of Health and Welfare School of Medicine

\section{Tatsuya Nagai}

Tokyo Bay Urayasu-Ichikawa Medical Center

\section{Satoru Ishikawa}

Funabashi Central Hospital

Nobuhisa Ishikawa

Hiroshima Prefectural Hospital

Yasuhiro Kondoh

Tosei General Hospital

Yoshitaka Yamazaki

Nagano Prefectural Shinshu Medical Center

Kyoko Gocho

Saiseikai Yokohamashi Tobu Hospital

Tomotaka Nishizawa

Japanese Red Cross Society Saitama Hospital

Akifumi Tsuzuku

Gifu Prefectural General Medical Center

Kazuma Yagi

Keiyu Hospital

Yuichiro Shindo

Nagoya University Graduate School of Medicine

Yuriko Takeda

Yokohama City University School of Medicine

Takeharu Yamanaka

Yokohama City University School of Medicine

Takashi Ogura

Kanagawa Cardiovascular and Respiratory Center

\section{Research Article}

Keywords: COVID-19, corticosteroid, propensity score matching, mortality, invasive mechanical ventilation

Posted Date: November 20th, 2020

DOl: https://doi.org/10.21203/rs.3.rs-112443/v1

License: () (1) This work is licensed under a Creative Commons Attribution 4.0 International License. Read Full License 


\section{Abstract}

Background. Corticosteroids use in coronavirus disease 2019 (COVID-19) is controversial, especially in mild to severe patients who do not require invasive/noninvasive ventilation. Moreover, many factors remain unclear regarding the appropriate use of corticosteroids for COVID-19. In this context, this multicenter, retrospective, propensity score-matched study was launched to evaluate the efficacy of systemic corticosteroid administration for hospitalized patients with COVID-19 ranging in the degree of severity from mild to critically-ill disease.

Methods. This multicenter, retrospective study enrolled consecutive hospitalized COVID-19 patients diagnosed January-April 2020 across 30 institutions in Japan. Clinical outcomes were compared for COVID-19 patients who received or did not receive corticosteroids, after adjusting for propensity scores. The primary endpoint was the odds ratio (OR) for improvement on a 7-point ordinal score on Day 15.

Results. Of 1092 COVID-19 patients analyzed, 118 patients were assigned to either the corticosteroid and non-corticosteroid group, after propensity score matching. At baseline, most patients did not require invasive/noninvasive ventilation ( $85.6 \%$ corticosteroid group vs. $89.8 \%$ non-corticosteroid group). The odds of improvement in a 7-point ordinal score on Day 15 was significantly lower for the corticosteroid versus non-corticosteroid group (OR, $0.611 ; 95 \%$ confidence interval $[\mathrm{Cl}], 0.388-0.962 ; p=0.034)$. The time to improvement in radiological findings was significantly shorter in the corticosteroid versus noncorticosteroid group (hazard ratio [HR], 1.758; $95 \% \mathrm{Cl}, 1.323-2.337 ; p<0.001$ ), regardless of baseline clinical status. The duration of invasive mechanical ventilation was shorter in corticosteroid versus non-corticosteroid group $(\mathrm{HR}, 1.466 ; 95 \% \mathrm{Cl}, 0.841-2.554 ; p=0.177)$. Of the 106 patients who received methylprednisolone, the duration of invasive mechanical ventilation was significantly shorter in the pulse/semi-pulse versus standard dose group (HR, 2.831; 95\% Cl, 1.347-5.950; $p=0.006)$.

Conclusions: Corticosteroids for hospitalized patients with COVID-19 did not improve clinical status on Day 15, but reduced the time to improvement in radiological findings for all patients regardless of disease severity and also reduced the duration of invasive mechanical ventilation in patients who required intubation.

Trial registration: This study was registered in the University hospital Medical Information Network Clinical Trials Registry on April 21, 2020 (ID: UMIN000040211).

\section{Background}

Approximately $20 \%$ of patients with coronavirus disease 2019 (COVID-19) develop severe pneumonia, and some of these patients progress to life-threatening respiratory failure, acute respiratory distress syndrome (ARDS) and multiple organ failure. ${ }^{1-2}$ Although the mechanisms of COVID-19-induced lung injury and multiple organ failure are still being elucidated, patients with severe COVID-19 versus mild to moderate disease have elevated concentrations of serum cytokines, suggesting the involvement of a "cytokine storm." ${ }^{2-5}$ This condition is associated with rapid deterioration in the severe acute respiratory syndrome coronavirus (SARS-CoV)-1 and Middle East respiratory syndrome coronavirus (MERS-CoV). ${ }^{6-8}$ If the COVID-19-induced lung injury worsens to the degree that invasive mechanical ventilation or extracorporeal membrane oxygen therapy (ECMO) is required, the mortality is very high. ${ }^{9-10}$ Therefore, appropriate antiinflammatory therapy to suppress the cytokine storm is considered crucial to prevent progression to irreversible ARDS and multiple organ failure. ${ }^{11-12}$

Corticosteroid therapy is a promising therapeutic candidate to suppress a cytokine storm, and has been widely used to treat previously prevalent SARS-CoV-1 and MERS-CoV. ${ }^{13-14}$ Recent results of several randomized trials of corticosteroids against COVID-19 have been reported, ${ }^{15-18}$ in which the therapy reduced the 28-day mortality and increased the number of ventilator-free days in critically ill patients with COVID-19. ${ }^{15-16}$ In light of these results, the latest World Health Organization (WHO) guidance recommends corticosteroids for severe and critical patients. ${ }^{19}$ On the other hands, most of the randomized trials reported so far did not include non-severe patients who did not require invasive or noninvasive ventilation. Only in the Randomized Evaluation of COVid-19 thERapY (RECOVERY) trial has the efficacy of corticosteroids for non-severe patients been validated, and corticosteroids failed to show a survival benefit for patients not receiving respiratory support, and might even be harmful. ${ }^{15}$ Based on this result alone, WHO guidance suggested not to use corticosteroids for the treatment of non-severe patients.

Therefore, the usefulness and necessity of corticosteroids for COVID-19 remains controversial, especially for the patients who do not require invasive or noninvasive ventilation. Moreover, many factors remain unclear regarding the appropriate use of corticosteroids for COVID-19, such as initial dose, administration period, and timing of initiation. In this context, this multicenter, retrospective, propensity score-matched study was launched to evaluate the efficacy of systemic corticosteroid administration for hospitalized patients with COVID-19 ranging in the degree of severity from mild to critically-ill disease. In addition, various subgroup analyses were performed to examine in detail the appropriate use of corticosteroids for COVID-19.

\section{Methods}

\section{Study design and participants}

This multicenter, retrospective study was conducted at 30 institutions in Japan. The study enrolled all consecutive patients who met the following inclusion criteria: (1) SARS-CoV-2 infection confirmed by polymerase chain reaction (PCR) test; (2) diagnosed between January 23-April 30, 2020; (3) required hospitalization for COVID-19; and (4) did not require home oxygen therapy before infection with COVID-19. Clinical and laboratory data were retrieved from patient medical records. Clinical outcomes for COVID-19 patients who received systemic corticosteroids (corticosteroid group) were compared with those who did not receive this therapy (non-corticosteroid group), after adjusting for propensity scores. The case registration period was from May $1-\mathrm{June} 30,2020$. 
This study was performed in accordance with the Declaration of Helsinki. The study protocol was approved by the Ethics Committee of the Kanagawa Cardiovascular and Respiratory Center (approval date: April 21, 2020, approved number: KCRC-20-0004), and the Institutional Review Board or Ethics Committee of other participating facilities. According to the Ethical Guidelines for Medical Research on Human Subjects in Japan, the opt-out method was used by publishing this study on either the participating facility's website or on a bulletin board. This study was registered in the University hospital Medical Information Network Clinical Trials Registry on April 21, 2020 (ID: UMIN000040211).

\section{Endpoints}

The primary endpoint was the odds ratio (OR) for improvement of the score on a 7-point ordinal scale on Day 15 , with the first day of hospitalization as Day 1. The ordinal scale is an assessment of the clinical status on a given day. The 7-point scale is as follows: (1) death; (2) hospitalized, on invasive mechanical ventilation or ECMO; (3) hospitalized, on noninvasive positive pressure ventilation (NIPPV) or high-flow nasal cannula (HFNC); (4) hospitalized, requiring low flow supplemental oxygen; (5) hospitalized, not requiring supplemental oxygen, requiring ongoing medical care; (6) hospitalized, not requiring supplemental oxygen, no longer required ongoing medical care; and (7) discharged/not hospitalized.

The key secondary endpoints were as follows: (1) time to PCR negativity of the swab solution; (2) duration of fever; (3) percentage of improvement in radiological findings; (4) time to improvement in radiological findings; (5) proportion of patients requiring invasive mechanical ventilation with tracheal intubation/ECMO; (6) time to requiring invasive mechanical ventilation with tracheal intubation; (7) duration of invasive mechanical ventilation with tracheal intubation; (8) hospitalization period, and (9) survival period.

\section{Propensity score matching}

The method of propensity score matching was used to minimize the bias due to confounding factors, assuming that an imbalance in patient background between the corticosteroid and non-corticosteroid groups may exist. The propensity score for each patient was calculated as a probability from a logistic regression model, including all covariates that were considered clinically important and had an impact on the patient's prognosis: (1) gender; (2) age; (3) body mass index; (4) smoking history; (5) comorbid hypertension; (6) comorbid diabetes mellitus; (7) time from symptom onset to admission; (8) score of 7-point ordinal scale on Day $1 ;(9)$ oxygen saturation $\left(\mathrm{SpO}_{2}\right)$ /fraction of inspired oxygen $\left(\mathrm{FiO}_{2}\right)$ on Day $1 ;(10)$ dyspnea; $(11)$ pneumonia on initial chest $\mathrm{X}$-ray or computed tomography (CT); (12) C-reactive protein (CRP); (13) concomitant use of favipiravir, and (14) concomitant use of any non-steroidal treatment for COVID-19.

\section{Statistical analysis}

In the primary analysis, ordinal variables were compared between groups using a proportional odds model. In the secondary and exploratory analysis, time to event was estimated using the Kaplan-Meier method. The Cox proportional hazards model was used to calculate the hazard ratio (HR) and its $95 \%$ confidence interval (Cl) for the treatment effect between groups. Categorical variables were presented as numbers (percentages), and compared using chi square test or Fisher exact test. Normally distributed continuous variables were presented as mean and standard deviation (SD), and compared using $t$ test. Continuous variables related to time were presented as median (interquartile ranges) and compared using $t$ test. A $p$ value $<0.05$ was considered statistically significant. All statistical analyses were performed using statistical software package SAS (version 9.4, SAS Institute).

\section{Results}

\section{Patient disposition}

Of 1141 consecutive hospitalized patients with COVID-19 registered by June 30, 2020, 49 patients were excluded from this study based on these criteria: (1) diagnosis after May 2020 (25 patients); (2) duplicate registrations from 2 facilities (11 patients); (3) no clinical status information for Day 1 due to transfer from another hospital (9 patients); (4) no need to be hospitalized (2 patients), (5) PCR testing only performed on spinal fluid (1 patient), and (6) negative results on PCR, but clinical diagnosis (1 patient). Thus, 1092 patients were included in the final analysis (Figure 1).

Clinical characteristics and prognosis of the 1092 patients analyzed are shown in Supplemental Table 1 and 2 . The mortality was $2.1 \%$ on Day 14 , and $3.8 \%$ on Day 28. Of the 235 patients who received corticosteroids for COVID-19, 163 (69.4\%) received early corticosteroids within 3 days after admission. The remaining 72 patients (30.6\%) who started corticosteroid $>4$ days after admission had a greater decline in $\mathrm{SpO}_{2} / \mathrm{FiO}_{2}$ from admission to just before corticosteroid initiation and a significantly worse score on the 7-point ordinal scale on Day 15 compared with the 163 early-treatment patients (Supplemental Table 3 and 4). In evaluating the efficacy of corticosteroids for the primary endpoint (improvement in clinical status on Day 15), the research team considered it inappropriate to include patients with delayed corticosteroid administration and worsening respiratory status; moreover, early corticosteroids have been reported to be effective against COVID-19. ${ }^{20}$ Therefore, the 163 patients who received early corticosteroids within 3 days after admission were designated as the unmatched corticosteroid group, and the 857 patients who did not receive corticosteroids for COVID-19 were categorized as the unmatched noncorticosteroid group. After propensity score matching, 118 patients were assigned to either the corticosteroid and non-corticosteroid groups. 


\section{Baseline characteristics before/after propensity score matching}

The distribution of the patients' baseline characteristics according to corticosteroid exposure is shown in Table 1, both in the unmatched and matched samples. The unmatched samples included a significantly higher number of male patients and those who were older age, had a higher weight and body mass index, and had more comorbidities (hypertension and diabetes) in the corticosteroid versus non-corticosteroid group. In addition, clinical and laboratory data for the corticosteroid versus non-corticosteroid group showed significantly poorer clinical status in a 7-point ordinal scale on $\mathrm{Day}_{1}$, lower $\mathrm{SpO}_{2} / \mathrm{FiO}_{2}$, higher rates of fever and dyspnea, higher CRP concentrations, and lower lymphocyte counts.

Standardized mean differences for each covariate before and after propensity score matching are shown in Figure 2 . The differences between corticosteroid and pretreatment variables were attenuated in the matched versus unmatched samples for propensity score. In fact, baseline characteristics were well balanced between the corticosteroid and non-corticosteroid groups after propensity score matching (Table 1). Regarding the baseline score on the 7-point ordinal scale in the matched samples, 4 was the most common score for both the corticosteroid and non-corticosteroid groups (44.9\% vs. $50.8 \%$ ), followed by a score of $5(40.7 \%$ vs. $39.0 \%)$.

Regarding the specific COVID-19 treatment administered both in the propensity score-unmatched and matched corticosteroid groups, nearly $90 \%$ of the corticosteroids administered for COVID-19 were methylprednisolone, with a median starting dose of $80 \mathrm{mg} /$ day and a mean administration period of 11.0 days (Table2).

\section{Primary Outcome}

The odds of improvement in a 7-point ordinal scale on Day 15 were significantly lower in the corticosteroid versus non-corticosteroid group (OR, $0.611 ; 95 \% \mathrm{Cl}$, $0.388-0.962 ; p=0.034$ ). (Table 3 ). In critically ill patients with a baseline 7-point ordinal score of 2 or 3 , the clinical status on Day 15 was similar in both groups (OR, $0.953 ; 95 \% \mathrm{Cl}, 0.215-4.224 ; p=0.950)$. In contrast, for patients with mild to severe disease with a baseline score of 4 or 5 , the odds of improvement were lower in the corticosteroid group than in the non-corticosteroid group.

\section{Key secondary outcomes}

The key secondary outcomes are shown in Table 4. No significant differences were observed between the two groups with respect to time to PCR negativity or duration of hospitalization. The duration of fever was significantly longer in the corticosteroid group (HR, $0.746 ; 95 \% \mathrm{Cl}, 0.560-0.994 ; p=0.045)$. The time to improvement in radiological findings was significantly shorter in the corticosteroid versus non-corticosteroid group (HR, 1.758; $95 \% \mathrm{Cl}, 1.323-2.337 ; p<0.001)$, regardless of baseline score of 7-point ordinal scale (Figure 3). The number of patients requiring invasive mechanical ventilation was higher in the corticosteroid versus non-corticosteroid group (33.9\% vs. $17.8 \% ; p=0.0072)$, with median time from admission to tracheal intubation of 2 days for both groups (Supplemental Figure 1). The duration of invasive mechanical ventilation was shorter in the corticosteroid versus non-corticosteroid group (HR, 1.466; $95 \% \mathrm{Cl}, 0.841-2.554 ; p=0.177)$ (Figure $4 \mathrm{~A})$. Mortality on Day 28 tended to be higher in the corticosteroid versus non-corticosteroid group $(10.2 \%$ vs. $4.2 \% ; \mathrm{p}=$ $0.1289)$, and the HR was $2.417(95 \% \mathrm{Cl}, 0.868-6.733 ; \mathrm{p}=0.091)$ (Supplemental Figure 2A).

\section{Subgroup analysis based on initial dose, administration period and timing of corticosteroids}

Subgroup analysis was performed based on initial dose, administration period, and timing of corticosteroids (Table 5). Of the 106 patients who received methylprednisolone, the duration of invasive mechanical ventilation was significantly shorter in the pulse/semi-pulse group (initial dose $\geq 250$ mg/day) than in the standard dose group (initial dose $<250 \mathrm{mg}$ /day) (median, 8 days vs. 15 days; HR, 2.831; 95\% Cl, 1.347-5.950; $p=0.006$ ) (Figure 4B). In the patients receiving corticosteroids for $\leq 10$ days, the time to PCR negativity of the swab solution tended to be shorter $(\mathrm{HR}, 1.437 ; 95 \% \mathrm{Cl}, 0.968-2.132 ; p=0.072)$ compared with the patients receiving corticosteroids for $>11$ days.

\section{Safety outcome}

Safety outcomes for both the corticosteroid and non-corticosteroid groups were also analyzed. Results showed no significant difference in the frequency of thromboembolism between the corticosteroid and non-corticosteroid groups (2.5\% vs. $3.4 \%)$.

\section{Discussion}

This study demonstrated the following 3 important clinical observations. First, corticosteroids did not lead to avoidance of tracheal intubation or lower mortality in patients with mild to severe COVID-19. Second, for the critically ill patients, corticosteroid therapy reduced not only the time to improvement in radiological findings, but also the duration of invasive mechanical ventilation. Third, methylprednisolone pulse/semi-pulse therapy significantly shortened the duration of invasive mechanical ventilation compared with the standard dose. 
In both the corticosteroid and non-corticosteroid groups, $>85 \%$ of patients did not require invasive or noninvasive ventilation at baseline. Because data are lacking on the benefit of corticosteroids for patients with mild to severe COVD-19 at baseline, the results of this study deserve to be noteworthy. In mild to severe patients with a baseline 7-point ordinal score of 4 or 5, the clinical status on Day 15 tended to be worse in the corticosteroid group than in the noncorticosteroid group. Administration of corticosteroids to patients with mild to severe COVD-19 was expected to prevent the progression to critical conditions that would require ECMO or invasive mechanical ventilation. However, a high proportion of patients in the corticosteroid group required invasive mechanical ventilation, despite the fact that corticosteroids reduced the time to improvement in radiological findings and suggested some benefit. This finding may have been due to the fact that the time from admission to tracheal intubation in patients who required invasive mechanical ventilation (median 2 days) was shorter than the time to improvement in imaging findings (median 8 days). Because corticosteroid treatment takes a certain amount of time to show benefit, it may not be expected to improve short-term outcomes, such as the avoidance of tracheal intubation.

This study also suggested that corticosteroids may have a negative impact on survival as assessed by Day 14 , Day 28 mortality, and the HR in mild to severe patients with a baseline 7-point ordinal score of 4 or 5 (Supplemental Figure 2C and 2D). Similarly, the RECOVERY study suggested that dexamethasone may rather worsen the prognosis among patients who were not receiving any respiratory support at randomization. ${ }^{15}$ Although there is concern that corticosteroid administration within 7 days of onset may inhibit antibody production, the median time from symptom onset to admission in the corticosteroid group in this study was 8.4 days. One possible explanation is that adverse effects of corticosteroids may have affected the prognosis. In the present study, no increase in thromboembolism was observed with corticosteroids. Although it cannot be ruled out that impaired hyperglycemic control and secondary infections may have an impact on prognosis, these data were not collected in this study and are a limitation for the application of study findings. However, it is questionable whether such events really have a significant impact on prognosis. Among the studies of COVID-19 patients requiring hospitalization and treatment, the patient population included in this study had a clearly better prognosis with a lower mortality than that described in many previous reports. ${ }^{21-22}$ Although the cause is unclear, the mortality is low not only in Japan, but also in most of the countries in East and Southeast Asia. ${ }^{23}$ In light of these findings, it may be difficult to draw definitive conclusions about the survival endpoint based on the results of this study, and caution should be used when comparing and interpreting data from this study with data from previous studies of populations in Europe and in North and South America.

Meanwhile, for the critically ill patients with a baseline ordinal score of 2 or 3, clinical status on Day 15 assessed by the 7-point ordinal scale was similar between the corticosteroid and non-corticosteroid groups. The present study showed 2 positive effects of corticosteroids as expected for critically ill COVID-19 patients. First, the reduction in the time to improvement in radiological findings may suggest the effectiveness of corticosteroids. Second, corticosteroids tended to reduce the duration of invasive mechanical ventilation, which is consistent with previous reports from randomized clinical trials. In the CoDEX trial, dexamethasone significantly increased the number of ventilator-free days in patients with moderate to severe ARDS who required intubation and ventilation. ${ }^{17}$ Although this study had a relatively small proportion of critical ill cases at baseline, early administration of corticosteroids to patients who develop severe respiratory failure requiring invasive or noninvasive ventilation may be beneficial.

It is also noteworthy that a subgroup analysis in this study showed that methylprednisolone pulse/semi-pulse therapy shortened the duration of mechanical intubation compared with the usual dose regimen. A small, single-blind, randomized, controlled, clinical trial in Iran reported that methylprednisolone pulse therapy (intravenous injection, $250 \mathrm{mg} /$ day for 3 days) reduced the time of clinical improvement and discharge from the hospital or death in severe hospitalized patients compared to the standard of care. ${ }^{24}$ However, to date, no previous reports have examined the differences in efficacy of different starting dose of corticosteroids. In contrast, subgroup analysis by administration period in this study suggested that prolonged corticosteroid administration over 11 days may prolong the time to PCR negativity. This result suggests that prolonged corticosteroid administration may delay the elimination of the virus from the body. Therefore, high-dose, short-term corticosteroid therapy should be considered in critically ill patients with COVID-19 pneumonia.

As a limitation of this study, even among the groups matched for propensity score, the corticosteroid group may still have included more rapidly deteriorating patients than the non-corticosteroid group. In fact, a higher rate of invasive mechanical ventilation (many of which cases are introduced within a few days), longer-lasting fevers despite corticosteroid therapy, and worsening of $\mathrm{SpO}_{2} / \mathrm{FiO}_{2}$ even in a short period of time from baseline to just before corticosteroid initiation were observed in the matched corticosteroid group. The biomarker to identify a rapidly deteriorating population among COVID-19 is not well established and may have been difficult, at least with the factors used for propensity score matching in this study. Although serum ferritin concentration could not be used for matching in this study because of the large number of deficiencies, this variable may be useful as a biomarker (serum ferritin concentration was measured for only 26 patients in the corticosteroid group [mean $1534.9 \mu \mathrm{g} / \mathrm{dL}$ ] and 51 in the non-corticosteroid group [mean $774.1 \mu \mathrm{g} / \mathrm{dL}$ ]). Detailed analysis of baseline CT images may also be a useful biomarker based on reports that the degree of extension of lung opacities and lung volume loss on CT had an impact on prognosis. ${ }^{25-28}$ As an additional limitation, it is necessary to discuss whether the endpoint using an ordinal scale was valid as a primary endpoint. None of the previously reported studies evaluating the efficacy of corticosteroids for COVID-19 have met the endpoint on an ordinal scale. ${ }^{17}$ Many infectious disease studies have relatively short-term measures set as primary endpoints, but the primary endpoint for the study of COVID-19 may need to be established with a longer-term perspective.

\section{Conclusions}

Corticosteroids for hospitalized patients with COVID-19 did not improve clinical status on Day 15. However, corticosteroids reduced the time to improvement in radiological findings in all patients regardless of disease severity. The duration of invasive mechanical ventilation in patients who had to be intubated was also reduced by corticosteroids, especially when started at higher doses as pulse/semi-pulse therapy.

\section{List Of Abbreviations}


ARDS, acute respiratory distress syndrome; Cl, Confidence interval; COVID-19, coronavirus disease 2019; CRP, C-reactive protein; CT, Computed tomography; ECMO, extracorporeal membrane oxygen therapy; WHO, World Health Organization; $\mathrm{FiO}_{2}$, fraction of inspired oxygen; HFNC, high-flow nasal cannula; HR, Hazard ratio; IL, interleukin; MERS-CoV, Middle East respiratory syndrome coronavirus; NIPPV, noninvasive positive pressure ventilation; OR, Odds ratio; PCR, polymerase chain reaction; $\mathrm{SARS}-\mathrm{CoV}$, severe acute respiratory syndrome coronavirus; $\mathrm{SD}$, standard deviation; $\mathrm{SpO}_{2}$, oxygen saturation.

\section{Declarations}

\section{Ethics approval and consent to participate}

The study protocol was approved by the Ethics Committee of the Kanagawa Cardiovascular and Respiratory Center (approval date: April 21, 2020, approved number: KCRC-20-0004), and the Institutional Review Board or Ethics Committee of other participating facilities. According to the Ethical Guidelines for Medical Research on Human Subjects in Japan, the opt-out method was used by publishing this study on either the participating facility's website or on a bulletin board.

\section{Consent for publication}

Not applicable.

\section{Availability of data and material}

The datasets generated during and/or analyzed during the current study are available from the corresponding author on reasonable request.

\section{Competing interests}

The authors declare no conflicts of interest directly relevant to the content of this article.

\section{Funding}

This study is supported by a research grant from Tokio Marine \& Nichido Fire Insurance Co., Ltd.

\section{Authors' contributions}

Satoshi Ikeda: Conceptualization, Methodology, Investigation, Data Curation, Writing (Original Draft). Toshihiro Misumi: Methodology, Formal analysis, Writing (Review \& Editing). Shinyu Izumi, Keita Sakamoto, Naoki Nishimura, Shosei Ro, Koichi Fukunaga, Satoshi Okamori, Natsuo Tachikawa, Nobuyuki Miyata, Masaharu Shinkai, Masahiro Shinoda, Yasunari Miyazaki, Yuki lijima, Takehiro Izumo, Minoru Inomata, Masaki Okamoto, Tomoyoshi Yamaguchi, Keisuke Iwabuchi, Makoto Masuda, Hiroyuki Takoi, Yoshitaka Oyamada, Shigeki Fujitani, Masamichi Mineshita, Haruyuki Ishii, Atsushi Nakagawa, Nobuhiro Yamaguchi, Makoto Hibino, Kenji Tsushima, Tatsuya Nagai, Satoru Ishikawa, Nobuhisa Ishikawa, Yasuhiro Kondoh, Yoshitaka Yamazaki, Kyoko Gocho, Tomotaka Nishizawa, Akifumi Tsuzuku, Kazuma Yagi, and Yuichiro Shindo: Investigation, Resources, Writing (Review \& Editing). Yuriko Takeda: Methodology, Formal analysis, Writing (Review \& Editing). Takeharu Yamanaka: Methodology, Formal analysis, Supervision, Writing (Review \& Editing), Takashi Ogura: Conceptualization, Methodology, Investigation, Project administration, Writing (Review \& Editing).

\section{Acknowledgements}

We would like to thank the patients, their families, and all the investigators who are participating in the present "DEFEAT COVID-19 (A Multicenter, Retrospective StuDy to Evaluate the EFficacy of SystEmic Glucocorticoid AgainsT COVID-19)" study. We would also like to express our sincere gratitude to Ms. Yukiko Ogasawara and Ms. Manami Kikuchi (Clinical Research Center, Kanagawa Cardiovascular and Respiratory Center, Japan) for their efforts in data management (checking and cleaning).

\section{References}

1. Cao X. COVID-19: immunopathology and its implications for therapy. Nat Rev Immunol 2020; 20(5):269-270.

2. Huang C, Wang Y, Li X, et al. Clinical features of patients infected with 2019 novel coronavirus in Wuhan, China. Lancet 2020; 395(10223):497-506.

3. Chen N, Zhou M, Dong X, et al. Epidemiological and clinical characteristics of 99 cases of 2019 novel coronavirus pneumonia in Wuhan, China: a descriptive study. Lancet 2020; 395(10223):507-13. 
4. Mehta P, McAuley DF, Brown M, et al. COVID-19: consider cytokine storm syndromes and immunosuppression. Lancet 2020; 395(10229):1033-4.

5. Bao J, Li C, Zhang K, Kang H, Chen W, Gu B. Comparative analysis of laboratory indexes of severe and non-severe patients infected with COVID-19. Clin Chim Acta 2020; 509:180-194.

6. de Wit E, van Doremalen N, Falzarano D, Munster VJ. SARS and MERS: recent insights into emerging coronaviruses. Nat Rev Microbio/ 2016; 14(8):523534.

7. Huang KJ, Su IJ, Theron M, et al. An interferon-gamma-related cytokine storm in SARS patients. J Med Virol 2005; 75(2):185-194.

8. Zhou J, Chu H, Li C, et al. Active replication of Middle East respiratory syndrome coronavirus and aberrant induction of inflammatory cytokines and chemokines in human macrophages: Implications for pathogenesis. J Infect Dis 2014;209(9):1331-1342.

9. Wu C, Chen X, Cai Y, et al. Risk factors associated with acute respiratory distress syndrome and death in patients with coronavirus disease 2019 pneumonia in Wuhan, China. JAMA Intern Med 2020; 180(7):1-11.

10. Qin C, Zhou L, Hu Z, et al. Dysregulation of immune response in patients with COVID-19 in Wuhan, China. Clin Infect Dis 2020: ciaa248.

11. McGonagle D, Sharif K, O'Regan A, Bridgewood C. The role of cytokines including interleukin-6 in COVID-19 induced pneumonia and macrophage activation syndrome-like disease. Autoimmun Rev 2020; 19(6):102537.

12. Hirano T, Murakami M. COVID-19: A new virus, but a familiar receptor and cytokine release syndrome. Immunity 2020; 52(5):731-733.

13. Stockman LJ, Bellamy R, Garner P. SARS: systematic review of treatment effects. PLoS Med 2006; 3(9):e343.

14. Arabi YM, Mandourah Y, Al-Hameed F, et al. corticosteroid therapy for critically ill patients with middle east respiratory syndrome. Am J Respir Crit Care Med 2018; 197(6):757-767.

15. RECOVERY Collaborative Group, Horby P, Lim WS, et al. Dexamethasone in hospitalized patients with Covid-19 - preliminary report. N Engl J Med 2020; NEJMoa2021436 [Online ahead of print].

16. Writing Committee for the REMAP-CAP Investigators, Angus DC, Derde L, et al. Effect of hydrocortisone on mortality and organ support in patients with severe COVID-19: The REMAP-CAP COVID-19 corticosteroid domain randomized clinical trial. JAMA [Online ahead of print]

17. Tomazini BM, Maia IS, Cavalcanti AB, et al. Effect of dexamethasone on days alive and ventilator-free in patients with moderate or severe acute respiratory distress syndrome and COVID-19: The CoDEX Randomized Clinical Trial. JAMA [Online ahead of print]

18. Dequin PF, Heming N, Meziani F, et al. Effect of hydrocortisone on 21-day mortality or respiratory support among critically ill patients with CoVID-19: A randomized clinical trial. JAMA [Online ahead of print]

19. World Health Organization. Corticosteroids for COVID-19: Living guidance 2 September 2020. https://www.who.int/publications-detail-redirect/WHO-2019nCoV-Corticosteroids-2020.1. Accessed 14 September 2020 [Internet].

20. Fadel R, Morrison AR, Vahia A, et al. Early short course corticosteroids in hospitalized patients with COVID-19. Clin Infect Dis [Online ahead of print]

21. Wiersinga WJ, Rhodes A, Cheng AC, Peacock SJ, Prescott HC. Pathophysiology, transmission, diagnosis, and treatment of coronavirus disease 2019 (COVID-19): A review. JAMA 2020; 324(8):782-793.

22. Richardson S, Hirsch JS, Narasimhan M, et al. Presenting characteristics, comorbidities, and outcomes among 5700 patients hospitalized with COVID-19 in the New York City Area. JAMA 2020; 323(20):2052-2059.

23. Johns Hopkins University \& Medicine. Coronavirus Resource Center. https://coronavirus.jhu.edu/data/mortality. Accessed 5 October 2020 [Internet].

24. Edalatifard M, Akhtari M, Salehi M, et al. Intravenous methylprednisolone pulse as a treatment for hospitalised severe COVID-19 patients: results from a randomised controlled clinical trial. Eur Respir J 2020 [Online ahead of print].

25. Colombi D, Bodini FC, Petrini M, et al. Well-aerated lung on admitting chest CT to predict adverse outcome in COVID-19 pneumonia. Radiology 2020; 296(2):E86-E96.

26. Liu F, Zhang Q, Huang C, et al. CT quantification of pneumonia lesions in early days predicts progression to severe illness in a cohort of COVID-19 patients. Theranostics 2020; 10(12):5613-5622.

27. Wang Y, Chen Y, Wei Y, et al. Quantitative analysis of chest CT imaging findings with the risk of ARDS in COVID-19 patients: a preliminary study. Ann Transl Med 2020; 8(9):594.

28. Iwasawa T, Sato M, Yamaya T, et al. Ultra-high-resolution computed tomography can demonstrate alveolar collapse in novel coronavirus (COVID-19) pneumonia. Jpn J Radiol 2020; 38(5): 394-398.

\section{Tables}

Table 1. Baseline Characteristics Before and After Propensity Score Matching 


\begin{tabular}{|c|c|c|c|c|c|c|}
\hline & \multicolumn{3}{|c|}{ Unmatched patients } & \multicolumn{3}{|c|}{ Propensity-Score Matched patients } \\
\hline & $\begin{array}{l}\text { Corticosteroid } \\
(\mathrm{N}=163)\end{array}$ & $\begin{array}{l}\text { Non- } \\
\text { corticosteroid } \\
(\mathrm{N}=857)\end{array}$ & $p$-value & $\begin{array}{l}\text { Corticosteroid } \\
(\mathrm{N}=118)\end{array}$ & $\begin{array}{l}\text { Non- } \\
\text { corticosteroid } \\
(\mathrm{N}=118)\end{array}$ & value \\
\hline \multicolumn{7}{|l|}{ Gender - no. (\%) } \\
\hline female & $44(27.0)$ & $322(37.6)$ & 0.01 & $34(28.8)$ & $38(32.2)$ & 0.572 \\
\hline male & $119(73.0)$ & $535(62.4)$ & & $84(71.2)$ & $80(67.8)$ & \\
\hline \multicolumn{7}{|l|}{ Age - no. (\%) } \\
\hline$<40 \mathrm{yr}$ & $16(9.8)$ & $253(29.5)$ & $<0.0001$ & $15(12.7)$ & $12(10.2)$ & 0.885 \\
\hline $40-59 y r$ & $59(36.2)$ & $275(32.1)$ & & $44(37.3)$ & $49(41.5)$ & \\
\hline $60-79 \mathrm{yr}$ & $65(39.9)$ & $264(30.8)$ & & $44(37.3)$ & $42(35.6)$ & \\
\hline$\geq 80 \mathrm{yr}$ & $23(14.1)$ & $65(7.6)$ & & $15(12.7)$ & $15(12.7)$ & \\
\hline Height - cm & $166.5 \pm 9.6$ & $166.1 \pm 9.8$ & 0.595 & $166.1 \pm 9.5$ & $165.4 \pm 9.9$ & 0.57 \\
\hline Body weight - kg & $69.9 \pm 18.3$ & $66.0 \pm 15.5$ & 0.008 & $69.0 \pm 17.9$ & $66.5 \pm 13.2$ & 0.231 \\
\hline \multicolumn{7}{|l|}{ Body Mass Index - no. (\%) } \\
\hline$<18.5$ & $4(2.8)$ & $55(7.9)$ & 0.083 & $3(2.5)$ & $1(0.8)$ & 0.584 \\
\hline$\geq 18.5,<25$ & $84(58.7)$ & $404(57.9)$ & & $70(59.3)$ & $73(61.9)$ & \\
\hline$\geq 25$ & $55(38.5)$ & $239(34.2)$ & & $45(38.1)$ & $44(37.3)$ & \\
\hline \multicolumn{7}{|l|}{ Race/region - no. (\%) } \\
\hline Japanese & $158(96.9)$ & $782(91.2)$ & 0.129 & $113(95.8)$ & $116(98.3)$ & 0.503 \\
\hline $\begin{array}{l}\text { East Asians outside of Japan (China, } \\
\text { Korea) }\end{array}$ & $3(1.8)$ & $15(1.8)$ & & $3(2.5)$ & $1(0.8)$ & \\
\hline South-East Asians & $2(1.2)$ & $27(3.2)$ & & $2(1.7)$ & $1(0.8)$ & \\
\hline Westerners - Caucasians & $0(0.0)$ & $30(3.5)$ & & & & \\
\hline Westerners - Blacks & $0(0.0)$ & $1(0.1)$ & & & & \\
\hline Others & $0(0.0)$ & $2(0.2)$ & & & & \\
\hline \multicolumn{7}{|l|}{ Smoking history - no. (\%) } \\
\hline Never & $91(59.9)$ & $456(59.1)$ & 0.854 & $72(61.0)$ & $74(62.7)$ & 0.789 \\
\hline Former or Current & $61(40.1)$ & $316(40.9)$ & & $46(39.0)$ & $44(37.3)$ & \\
\hline \multicolumn{7}{|l|}{ Comorbidities - no. (\%) } \\
\hline Hypertension & $64(39.3)$ & $200(23.3)$ & $<0.0001$ & $42(35.6)$ & $37(31.4)$ & 0.49 \\
\hline Diabetes mellitus & $50(30.7)$ & $118(13.8)$ & $<0.0001$ & $33(28.0)$ & $34(28.8)$ & 0.885 \\
\hline Time from symptom onset to admission - days & $8.4 \pm 4.3$ & $8.2 \pm 4.8$ & 0.551 & $8.4 \pm 4.4$ & $8.4 \pm 3.4$ & 1 \\
\hline \multicolumn{7}{|l|}{ Score of 7-point ordinal scale on Day 1 - no. (\%) } \\
\hline 2 or 3 & $32(19.6)$ & $21(2.5)$ & $<0.0001$ & $15(12.7)$ & $9(7.6)$ & 0.537 \\
\hline 4 & $74(45.4)$ & $168(19.6)$ & & $53(44.9)$ & $60(50.8)$ & \\
\hline 5 & $54(33.1)$ & $310(36.2)$ & & $48(40.7)$ & $46(39.0)$ & \\
\hline 6 & $3(1.8)$ & $358(41.8)$ & & $2(1.7)$ & $3(2.5)$ & \\
\hline \multicolumn{7}{|l|}{ Sp02/FiO2 } \\
\hline On Day 1 & $342.1 \pm 130.5$ & $435.1 \pm 70.7$ & $<0.0001$ & $372.7 \pm 112.7$ & $383.3 \pm 105.3$ & 0.457 \\
\hline Just before corticosteroid initiation & $292.9 \pm 139.2$ & & & $318.8 \pm 132.4$ & & \\
\hline \multicolumn{7}{|l|}{ Symptoms due to COVID-19 } \\
\hline Fever $\geq 37^{\circ} \mathrm{C}-$ no. $(\%)$ & $126(77.3)$ & $525(61.3)$ & $<0.0001$ & $95(80.5)$ & $86(72.9)$ & 0.166 \\
\hline Dyspnea - no. (\%) & $92(56.4)$ & $249(29.1)$ & $<0.0001$ & $63(53.4)$ & $58(49.2)$ & 0.515 \\
\hline Taste and/or smell disorder - no. (\%) & $19(11.7)$ & $198(23.1)$ & 0.001 & $15(12.7)$ & $25(21.2)$ & 0.083 \\
\hline
\end{tabular}

Page 9/18 


\begin{tabular}{|c|c|c|c|c|c|c|}
\hline Pneumonia on initial Xp/CT - no. (\%) & $159(97.5)$ & $600(70.0)$ & $<0.0001$ & $116(98.3)$ & $116(98.3)$ & 1 \\
\hline \multicolumn{7}{|l|}{ Laboratory data } \\
\hline C-reactive protein - mg/dL & $9.7 \pm 7.1$ & $4.4 \pm 5.7$ & $<0.0001$ & $8.6 \pm 6.9$ & $8.3 \pm 7.5$ & 0.748 \\
\hline Lymphocyte count - / $\mu \mathrm{L}$ & $861.8 \pm 592.2$ & $1193.9 \pm 588.2$ & $<0.0001$ & $848.2 \pm 646.6$ & $1005.8 \pm 589.1$ & 0.062 \\
\hline
\end{tabular}

Because only a few patients had a baseline 7-point ordinal score of 3, the patients with a baseline score of 2 and 3 were combined for the analysis. Categorical variables were presented as numbers (\%), and compared using the chi square test. Normally distributed continuous variables were presented as mean and standard deviation (SD), and compared using the $t$ test. A $p$ value of $<0.05$ was considered statistically significant. COVID- 19 , coronavirus disease 2019; CT, computed tomography.

Table 2. Treatment for Coronavirus Disease 2019

\begin{tabular}{|c|c|c|c|c|c|c|}
\hline & \multicolumn{3}{|c|}{ Unmatched patients } & \multicolumn{3}{|c|}{ Propensity-Score Matched patients } \\
\hline & $\begin{array}{l}\text { Corticosteroid } \\
(\mathrm{N}=163)\end{array}$ & $\begin{array}{l}\text { Non- } \\
\text { corticosteroid } \\
(\mathrm{N}=857)\end{array}$ & $p$-value & $\begin{array}{l}\text { Corticosteroid } \\
(\mathrm{N}=118)\end{array}$ & $\begin{array}{l}\text { Non- } \\
\text { corticosteroid } \\
(\mathrm{N}=118)\end{array}$ & $p$-value \\
\hline \multicolumn{7}{|l|}{ Corticosteroids for COVID-19 } \\
\hline Methylprednisolone & $144(88.3)$ & - & & $106(89.8)$ & - & \\
\hline \multicolumn{7}{|l|}{ Starting dose } \\
\hline Median - mg/day & 80 & - & & 80 & - & \\
\hline $\begin{array}{l}\text { Minimum-Maximum - } \\
\text { mg/day }\end{array}$ & $12-1000$ & - & & $12-1000$ & - & \\
\hline Duration of administration - days & $11.0[5.0,16.0]$ & - & & $11.0[6.0,15.8]$ & - & \\
\hline Oral prednisolone & $7(4.3)$ & - & & $5(4.2)$ & - & \\
\hline \multicolumn{7}{|l|}{ Starting dose } \\
\hline Median - mg/day & 40 & - & & 40 & - & \\
\hline $\begin{array}{l}\text { Minimum-Maximum - } \\
\mathrm{mg} / \text { day }\end{array}$ & $30-80$ & - & & $30-55$ & - & \\
\hline Duration of administration - days & $\begin{array}{l}15.0[12.5 \\
17.5]\end{array}$ & - & & $\begin{array}{l}15.0[15.0 \\
18.0]\end{array}$ & - & \\
\hline Dexamethasone & $6(3.7)$ & - & & $1(0.8 \%)$ & - & \\
\hline \multicolumn{7}{|l|}{ Starting dose } \\
\hline Median - mg/day & 16 & - & & 80 & - & \\
\hline $\begin{array}{l}\text { Minimum-Maximum - } \\
\text { mg/day }\end{array}$ & $8-80$ & - & & - & - & \\
\hline Duration of administration - days & $9.0[8.0,10.0]$ & - & & 20.0 & - & \\
\hline Others - no. (\%) & $6(3.7)$ & - & & $6(5.1 \%)$ & - & \\
\hline \multicolumn{7}{|l|}{ Non-steroidal treatment for COVID-19 } \\
\hline None - no. (\%) & $1(0.6)$ & $286(33.4)$ & $<0.0001$ & $1(0.8)$ & 0 & 0.316 \\
\hline Favipiravir - no. (\%) & $98(60.1)$ & $275(32.1)$ & $<0.0001$ & $73(61.9)$ & $79(66.9)$ & 0.415 \\
\hline Lopinavir/ritonavir - no. (\%) & $6(3.7)$ & $48(5.6)$ & 0.316 & $5(4.2)$ & $11(9.3)$ & 0.12 \\
\hline Chloroquine - no. (\%) & $33(20.2)$ & $108(12.6)$ & 0.01 & $14(11.9)$ & $18(15.3)$ & 0.447 \\
\hline Ciclesonide-no. (\%) & $35(21.5)$ & $201(23.5)$ & 0.582 & $22(18.6)$ & $41(34.7)$ & 0.005 \\
\hline Tocilizumab - no. (\%) & $6(3.7)$ & $8(0.9)$ & 0.006 & $3(2.5)$ & $1(0.8)$ & 0.313 \\
\hline Macrolide-no. (\%) & $114(69.9)$ & $215(25.1)$ & $<0.0001$ & $81(68.6)$ & $36(30.5)$ & $<0.0001$ \\
\hline Immunoglobulin - no. (\%) & $9(5.5)$ & $14(1.6)$ & 0.002 & $8(6.8)$ & $6(5.1)$ & 0.582 \\
\hline Others - no. (\%) & $102(62.6)$ & $166(19.4)$ & $<0.0001$ & $80(67.8)$ & $30(25.4)$ & $<0.0001$ \\
\hline
\end{tabular}


Categorical variables were presented as numbers (\%), and compared using the chi square test. Continuous variables related to time were presented as median [interquartile ranges] and compared using the $t$ test. A $p$ value of $<0.05$ was considered statistically significant. COVID-19, coronavirus disease 2019.

Table 3. Primary Outcome

\begin{tabular}{|c|c|c|c|c|c|c|c|c|}
\hline & \multirow{2}{*}{\multicolumn{2}{|c|}{ Overall }} & \multicolumn{6}{|c|}{ Score of 7-point ordinal scale on Day 1 (baseline) } \\
\hline & & & \multicolumn{2}{|l|}{2,3} & \multicolumn{2}{|l|}{4} & \multicolumn{2}{|l|}{5} \\
\hline & Corticosteroid & $\begin{array}{l}\text { Non- } \\
\text { corticosteroid }\end{array}$ & Corticosteroid & $\begin{array}{l}\text { Non- } \\
\text { corticosteroid }\end{array}$ & Corticosteroid & $\begin{array}{l}\text { Non- } \\
\text { corticosteroid }\end{array}$ & Corticosteroid & $\begin{array}{l}\mathrm{N} \text { 1 } \\
\mathrm{CC}\end{array}$ \\
\hline & $(\mathrm{N}=118)$ & $(\mathrm{N}=118)$ & $(\mathrm{N}=15)$ & $(\mathrm{N}=9)$ & $(\mathrm{N}=53)$ & $(\mathrm{N}=60)$ & $(\mathrm{N}=48)$ & $(\wedge$ \\
\hline \multicolumn{9}{|l|}{$\begin{array}{l}\text { Score of 7- } \\
\text { point ordinal } \\
\text { scale on Day } \\
15-\text { no. (\%) }\end{array}$} \\
\hline 1 & $7(5.9)$ & $3(2.5)$ & $2(13.3)$ & 0 & $3(5.7)$ & $3(5.0)$ & $2(4.2)$ & 0 \\
\hline 2 & $16(13.6)$ & $12(10.2)$ & $2(13.3)$ & $3(33.3)$ & $10(18.9)$ & $9(15.0)$ & $3(6.3)$ & 0 \\
\hline 3 & $4(3.4)$ & $1(0.8)$ & $1(6.7)$ & 0 & $2(3.8)$ & $1(1.7)$ & $1(2.1)$ & 0 \\
\hline 4 & $29(24.6)$ & $22(18.6)$ & $5(33.3)$ & $4(44.4)$ & $19(35.8)$ & $16(26.7)$ & $4(8.3)$ & 1 \\
\hline 5 & $20(16.9)$ & $27(22.9)$ & $3(20.0)$ & 0 & $4(7.5)$ & $10(16.7)$ & $13(27.1)$ & $1 \epsilon$ \\
\hline 6 & $16(13.6)$ & $21(17.8)$ & $2(13.3)$ & $2(22.2)$ & $10(18.9)$ & $11(18.3)$ & $4(8.3)$ & 7 \\
\hline 7 & $26(22.0)$ & $32(27.1)$ & 0 & 0 & $5(9.4)$ & $10(16.7)$ & $21(43.8)$ & $2 ;$ \\
\hline $\begin{array}{l}\text { Odds } \\
\text { ratio } \\
(95 \% \mathrm{Cl})\end{array}$ & \multicolumn{2}{|c|}{$0.611 ه 0.388-0.962 \rrbracket$} & \multicolumn{2}{|c|}{$0.953 \llbracket 0.215-4.224 \rrbracket$} & \multicolumn{2}{|c|}{$0.626 \llbracket 0.323-1.213 \rrbracket$} & \multicolumn{2}{|c|}{$0.589 ه 0.277-1.25$ 다 } \\
\hline p-value & \multicolumn{2}{|l|}{0.034} & \multicolumn{2}{|l|}{0.950} & \multicolumn{2}{|l|}{0.165} & \multicolumn{2}{|l|}{0.170} \\
\hline
\end{tabular}

Because only a few patients had a baseline 7-point ordinal score of 3, the patients with a baseline score of 2 and 3 were combined for the analysis. Categorical variables were presented as numbers (\%). Ordinal variables were compared between groups using a proportional odds model. A $p$ value of $<0.05$ was considered statistically significant. $\mathrm{Cl}$, confidence interval

Table 4. Secondary Outcomes 


\begin{tabular}{|c|c|c|c|c|c|c|c|}
\hline & \multirow{2}{*}{\multicolumn{2}{|c|}{ Overall }} & \multicolumn{5}{|c|}{ Score of 7-point ordinal scale on Day 1 (baseline) } \\
\hline & & & \multicolumn{2}{|l|}{2,3} & \multicolumn{2}{|l|}{4} & \multirow{2}{*}{$\begin{array}{l}5 \\
\text { Corticosteroid }\end{array}$} \\
\hline & Corticosteroid & $\begin{array}{l}\text { Non- } \\
\text { corticosteroid }\end{array}$ & Corticosteroid & $\begin{array}{l}\text { Non- } \\
\text { corticosteroid }\end{array}$ & Corticosteroid & $\begin{array}{l}\text { Non- } \\
\text { corticosteroid }\end{array}$ & \\
\hline & $(\mathrm{N}=118)$ & $(\mathrm{N}=118)$ & $(\mathrm{N}=15)$ & $(\mathrm{N}=9)$ & $(\mathrm{N}=53)$ & $(\mathrm{N}=60)$ & $(\mathrm{N}=48)$ \\
\hline \multicolumn{8}{|l|}{$\begin{array}{l}\text { Time to PCR } \\
\text { negativity of the } \\
\text { swab solution }\end{array}$} \\
\hline $\begin{array}{l}\text { Median } \\
\text { [IQR] - days }\end{array}$ & $19[10,24]$ & $18[12,24]$ & $21[15,26]$ & $46[23,-]$ & $21[15,27]$ & $19[13,28]$ & $13[8,23]$ \\
\hline $\begin{array}{l}\text { Hazard } \\
\text { ratio } \\
(95 \% \mathrm{Cl})\end{array}$ & \multicolumn{2}{|c|}{$1.091(0.828-1.437)$} & \multicolumn{2}{|c|}{$3.008(0.948-9.543)$} & \multicolumn{2}{|c|}{$0.908(0.608-1.356)$} & $1.146(0.743-1$ \\
\hline$p$-value & \multicolumn{2}{|l|}{0.535} & \multicolumn{2}{|l|}{0.062} & \multicolumn{2}{|l|}{0.637} & 0.538 \\
\hline \multicolumn{8}{|l|}{ Duration of fever } \\
\hline $\begin{array}{l}\text { Median } \\
\text { [IQR] - days }\end{array}$ & $8.5[4,16]$ & $6[4,12]$ & $7.5[5,28]$ & $9.5[3.5,18.5]$ & $7.5[4,14]$ & $9[5,20]$ & $10[6,30]$ \\
\hline $\begin{array}{l}\text { Hazard } \\
\text { ratio } \\
(95 \% \mathrm{Cl})\end{array}$ & \multicolumn{2}{|c|}{$0.746(0.560-0.994)$} & \multicolumn{2}{|c|}{$0.765(0.289-2.022)$} & \multicolumn{2}{|c|}{$1.231(0.823-1.843)$} & $0.251(0.147-C$ \\
\hline$p$-value & \multicolumn{2}{|l|}{0.045} & \multicolumn{2}{|l|}{0.589} & \multicolumn{2}{|l|}{0.312} & $<0.001$ \\
\hline $\begin{array}{l}\text { Improvement in } \\
\text { radiological } \\
\text { findings - No. (\%) }\end{array}$ & $103(87.3)$ & $90(76.3)$ & $12(80.0)$ & $6(66.7)$ & $45(84.9)$ & $42(70.0)$ & 44 (91.7) \\
\hline \multicolumn{8}{|l|}{$\begin{array}{l}\text { Time to } \\
\text { improvement in } \\
\text { radiological } \\
\text { findings }\end{array}$} \\
\hline $\begin{array}{l}\text { Median } \\
\text { [IQR] - days }\end{array}$ & $8[5,18]$ & $14[9,29]$ & $6.5[4,12]$ & $26[15,61]$ & $10[6,23]$ & $14[10,36]$ & $7[5,13]$ \\
\hline $\begin{array}{l}\text { Hazard } \\
\text { ratio } \\
(95 \% \mathrm{Cl})\end{array}$ & \multicolumn{2}{|c|}{$1.758(1.323-2.337)$} & \multicolumn{2}{|c|}{$3.812(1.285-11.303)$} & \multicolumn{2}{|c|}{$1.541(1.012-2.349)$} & $1.86\left(1.193-2 .{ }^{\prime}\right.$ \\
\hline$p$-value & \multicolumn{2}{|l|}{$<0.001$} & \multicolumn{2}{|l|}{0.016} & \multicolumn{2}{|l|}{0.044} & 0.006 \\
\hline $\begin{array}{l}\text { Invasive } \\
\text { mechanical } \\
\text { ventilation - No. } \\
(\%)\end{array}$ & $40(33.9)$ & $21(17.8)$ & $11(73.3)$ & $9(100)$ & $23(43.4)$ & $12(20)$ & $5(10.4)$ \\
\hline $\begin{array}{l}\text { Extra-Corporeal } \\
\text { Membrane } \\
\text { Oxygenation - } \\
\text { No. (\%) }\end{array}$ & $7(5.9)$ & $7(5.9)$ & $1(6.7)$ & $2(22.2)$ & $5(9.4)$ & $5(8.3)$ & $1(2.1)$ \\
\hline \multicolumn{8}{|l|}{$\begin{array}{l}\text { Duration of } \\
\text { invasive } \\
\text { mechanical } \\
\text { ventilation }\end{array}$} \\
\hline $\begin{array}{l}\text { Median } \\
\text { [IQR] - days }\end{array}$ & $10[8,18]$ & $17[10,26]$ & $8[6,12]$ & $12[6,17]$ & $10[9,25]$ & $20.5[12,31]$ & \\
\hline $\begin{array}{l}\text { Hazard } \\
\text { ratio } \\
(95 \% \mathrm{Cl})\end{array}$ & \multicolumn{2}{|c|}{$1.466(0.841-2.554)$} & \multicolumn{2}{|c|}{$1.808(0.691-4.730)$} & \multicolumn{2}{|c|}{$1.642(0.773-3.489)$} & - \\
\hline$p$-value & \multicolumn{2}{|l|}{0.177} & \multicolumn{2}{|l|}{0.227} & 0.197 & & - \\
\hline $\begin{array}{l}\text { Hospitalization } \\
\text { period }\end{array}$ & & & & & & & \\
\hline $\begin{array}{l}\text { Median } \\
\text { [IQR] - days }\end{array}$ & $24[15,34]$ & $21[14,29]$ & $27[20,33]$ & $27[26,34]$ & $30[20,47]$ & $23[17,37]$ & $16.5[11,26]$ \\
\hline $\begin{array}{l}\text { Hazard } \\
\text { ratio } \\
(95 \% \mathrm{Cl})\end{array}$ & $0.861(0.659-1$ & 125) & $1.623(0.649-4$ & 054) & $0.789(0.530-$ & 176) & $0.797(0.523-1$ \\
\hline$p$-value & 0.272 & & 0.300 & & 0.244 & & 0.293 \\
\hline
\end{tabular}

Mortality - No. 
(\%)

\begin{tabular}{|c|c|c|c|c|c|c|c|}
\hline on Day 14 & $7(5.9)$ & $3(2.5)$ & $2(13.3)$ & 0 & $3(5.7)$ & $3(5.0)$ & $2(4.2)$ \\
\hline$p$-value & 0.333 & & 0.511 & & 1.000 & & 0.495 \\
\hline on Day 28 & $12(10.2)$ & $5(4.2)$ & $3(20.0)$ & $1(11.1)$ & $6(11.3)$ & $4(6.7)$ & $3(6.3)$ \\
\hline$p$-value & 0.129 & & 1.000 & & 0.512 & & 0.242 \\
\hline $\begin{array}{l}\text { during the } \\
\text { entire } \\
\text { observation } \\
\text { period }\end{array}$ & $14(11.9)$ & $5(4.2)$ & $3(20.0)$ & $1(11.1)$ & $7(13.2)$ & $4(6.7)$ & $4(8.3)$ \\
\hline \multicolumn{8}{|l|}{ Survival period } \\
\hline $\begin{array}{l}\text { Hazard } \\
\text { ratio } \\
(95 \% \mathrm{Cl})\end{array}$ & \multicolumn{2}{|c|}{$2.417(0.868-6.733)$} & \multicolumn{2}{|c|}{1.900 (0.198 - 18.273) } & \multicolumn{2}{|c|}{$1.744(0.509-5.969)$} & - \\
\hline$p$-value & \multicolumn{2}{|l|}{0.091} & \multicolumn{2}{|l|}{0.578} & \multicolumn{2}{|l|}{0.376} & 0 \\
\hline
\end{tabular}

Because only a few patients had a baseline 7-point ordinal score of 3, the patients with a baseline score of 2 and 3 were combined for the analysis. Categorical variables were presented as numbers (\%). IQR, interquartile ranges; Cl, confidence interval; PCR, polymerase chain reaction.

Table 5. Subgroup Analysis in the Propensity-Score Matched Corticosteroid Group 


\begin{tabular}{|c|c|c|c|c|c|c|}
\hline & \multicolumn{2}{|c|}{$\begin{array}{l}\text { Initial dose of } \\
\text { methylprednisolone } \\
(\mathrm{N}=106)\end{array}$} & \multicolumn{2}{|c|}{$\begin{array}{l}\text { Administration period } \\
(\mathrm{N}=118)\end{array}$} & \multicolumn{2}{|c|}{$\begin{array}{l}\text { Timing of corticosteroids } \\
\text { initiation } \\
(\mathrm{N}=118)\end{array}$} \\
\hline & $\begin{array}{l}\text { pulse/semi- } \\
\text { pulse }\end{array}$ & $\begin{array}{l}\text { standard } \\
\text { dose }\end{array}$ & $\begin{array}{l}\leq 10 \\
\text { days }\end{array}$ & $>11$ days & on day 1 & on day 2 or 3 \\
\hline & $(\mathrm{N}=30)$ & $(\mathrm{N}=76)$ & $(\mathrm{N}=55)$ & $(\mathrm{N}=63)$ & $(\mathrm{N}=70)$ & $(\mathrm{N}=48)$ \\
\hline \multicolumn{7}{|l|}{$\begin{array}{l}\text { Time to PCR negativity of the swab } \\
\text { solution }\end{array}$} \\
\hline Median [IQR] - days & $22[15,24]$ & $15[9,24]$ & $15[8,24]$ & $\begin{array}{l}21[14, \\
26]\end{array}$ & $15[9,24]$ & $20[15,27]$ \\
\hline Hazard ratio $(95 \% \mathrm{Cl})$ & \multicolumn{2}{|c|}{$0.854(0.537-1.358)$} & \multicolumn{2}{|c|}{$1.437(0.968-2.132)$} & \multicolumn{2}{|c|}{$0.753(0.504-1.124)$} \\
\hline$p$-value & \multicolumn{2}{|l|}{0.505} & \multicolumn{2}{|l|}{0.072} & \multicolumn{2}{|l|}{0.165} \\
\hline \multicolumn{7}{|l|}{ Duration of fever } \\
\hline Median [IQR] - days & $8[4,16]$ & $10[5,19]$ & $6[4,15]$ & $11[6,28]$ & $8[4,15]$ & $10[4,19]$ \\
\hline Hazard ratio $(95 \% \mathrm{Cl})$ & \multicolumn{2}{|c|}{$1.037(0.639-0.1 .683)$} & \multicolumn{2}{|c|}{1.337 (0.886 - 2.019) } & \multicolumn{2}{|c|}{$0.927(0.610-1.407)$} \\
\hline$p$-value & \multicolumn{2}{|l|}{0.882} & \multicolumn{2}{|l|}{0.167} & \multicolumn{2}{|l|}{0.720} \\
\hline \multicolumn{7}{|l|}{$\begin{array}{l}\text { Time to improvement in radiological } \\
\text { findings }\end{array}$} \\
\hline Median [IQR] - days & $11[4,23]$ & $8[6,16]$ & $7[5,14]$ & $9[6,18]$ & $7[5,16]$ & $8.5[6,18]$ \\
\hline Hazard ratio $(95 \% \mathrm{Cl})$ & \multicolumn{2}{|c|}{$0.880(0.554-1.399)$} & \multicolumn{2}{|c|}{$1.124(0.760-1.662)$} & \multicolumn{2}{|c|}{$0.855(0.576-1.271)$} \\
\hline$p$-value & \multicolumn{2}{|l|}{0.589} & \multicolumn{2}{|l|}{0.557} & \multicolumn{2}{|l|}{0.439} \\
\hline Invasive mechanical ventilation - No. (\%) & $17(56.7)$ & $17(22.4)$ & $9(16.4)$ & $31(49.2)$ & $18(25.7)$ & $22(45.8)$ \\
\hline \multicolumn{7}{|l|}{$\begin{array}{l}\text { Duration of invasive mechanical } \\
\text { ventilation }\end{array}$} \\
\hline Median [IQR] - days & $8[6,10]$ & $15[10,26]$ & $10[8,16]$ & $11[8,18]$ & $10[7,13]$ & $11.5[9,23]$ \\
\hline Hazard ratio $(95 \% \mathrm{Cl})$ & \multicolumn{2}{|c|}{$2.831(1.347-5.950)$} & \multicolumn{2}{|c|}{$1.247(0.588-2.646)$} & \multicolumn{2}{|c|}{$0.713(0.374-1.358)$} \\
\hline$p$-value & \multicolumn{2}{|l|}{0.006} & \multicolumn{2}{|l|}{0.565} & \multicolumn{2}{|l|}{0.304} \\
\hline \multicolumn{7}{|l|}{ Mortality - No. (\%) } \\
\hline on Day 14 & $2(6.7)$ & $5(6.6)$ & $5(9.1)$ & $2(3.2)$ & $3(4.3)$ & $4(8.3)$ \\
\hline on Day 28 & $4(13.3)$ & $6(7.9)$ & $6(10.9)$ & $6(9.5)$ & $6(8.6)$ & $6(12.5)$ \\
\hline during the entire observation period & $4(13.3)$ & $8(10.5)$ & $7(12.7)$ & $7(11.1)$ & $6(8.6)$ & $8(16.7)$ \\
\hline
\end{tabular}

Categorical variables were presented as numbers (percentages). Continuous variables related to time were presented as median [interquartile ranges]. Cox proportional hazards model was used to calculate the hazard ratio and its $95 \%$ confidence interval for the treatment effect between groups. A $p$ value of $<0.05$ was considered statistically significant. IQR, interquartile ranges; $\mathrm{Cl}$, confidence interval; PCR, polymerase chain reaction.

\section{Figures}




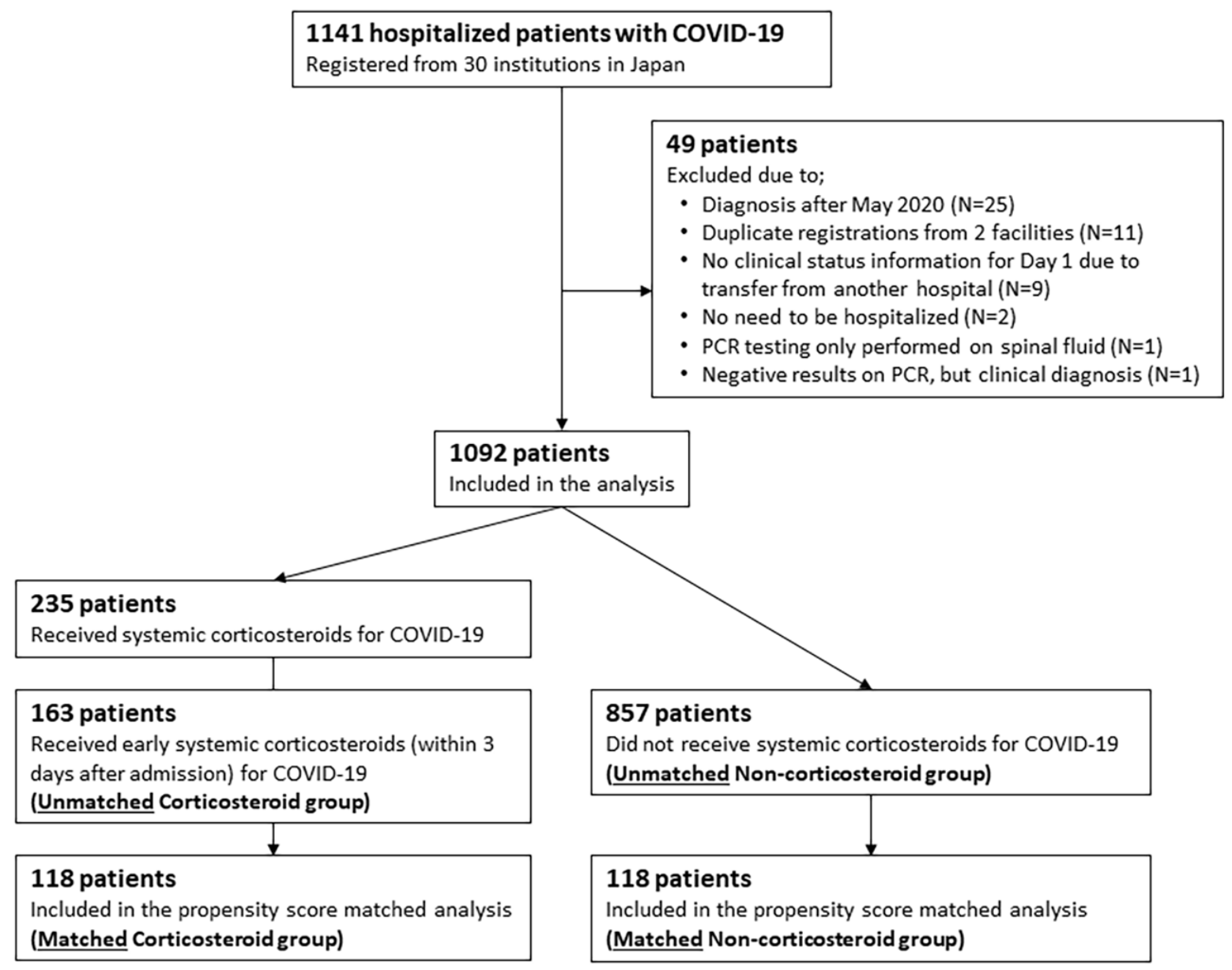

Figure 1

Patient Disposition COVID-19, coronavirus disease 2019; PCR, polymerase chain reaction. 

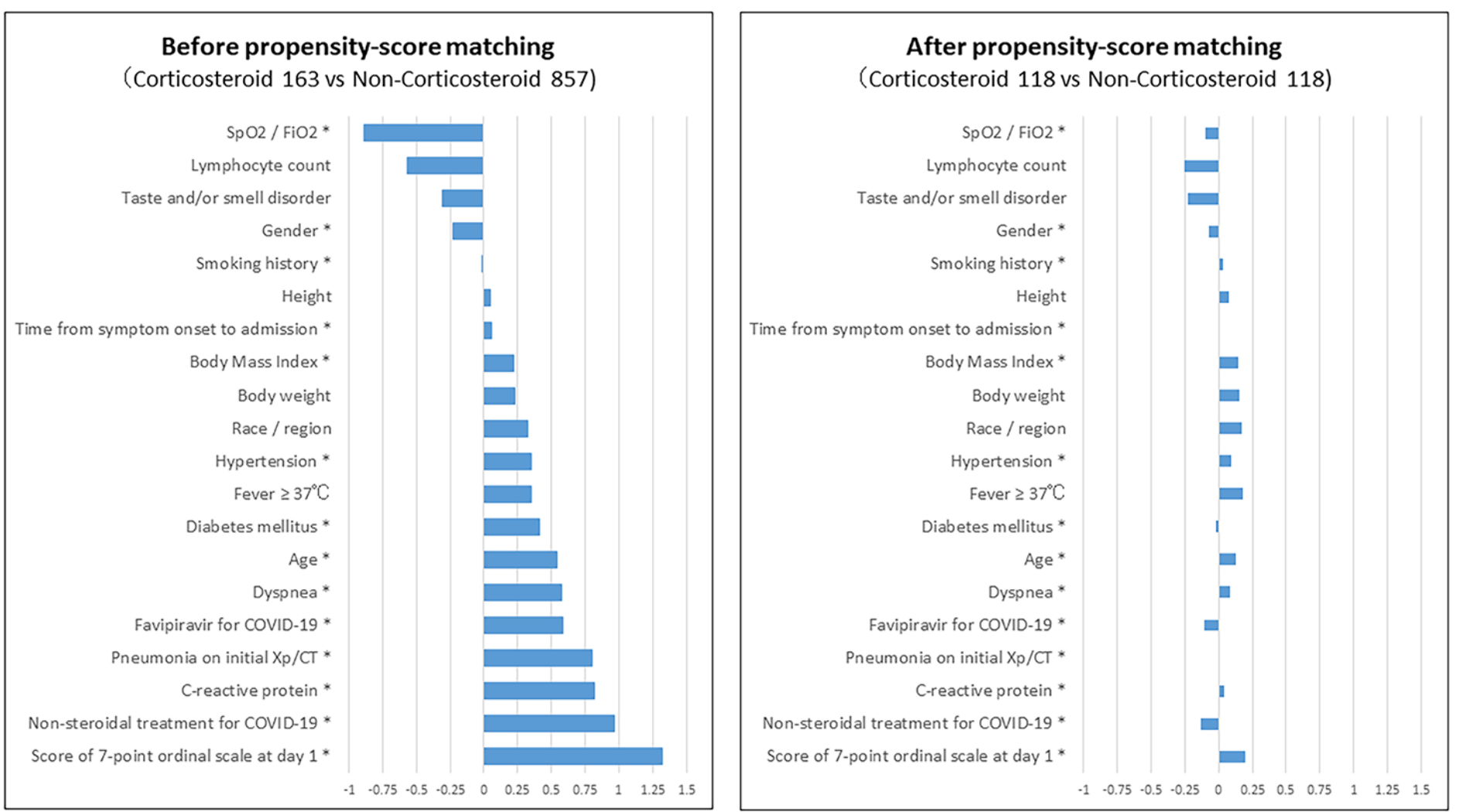

\section{Figure 2}

Standardized Mean Difference Before and After Propensity Score Matching * Covariates used for propensity score matching. COVID-19, coronavirus disease 2019; CT, computed tomography. 


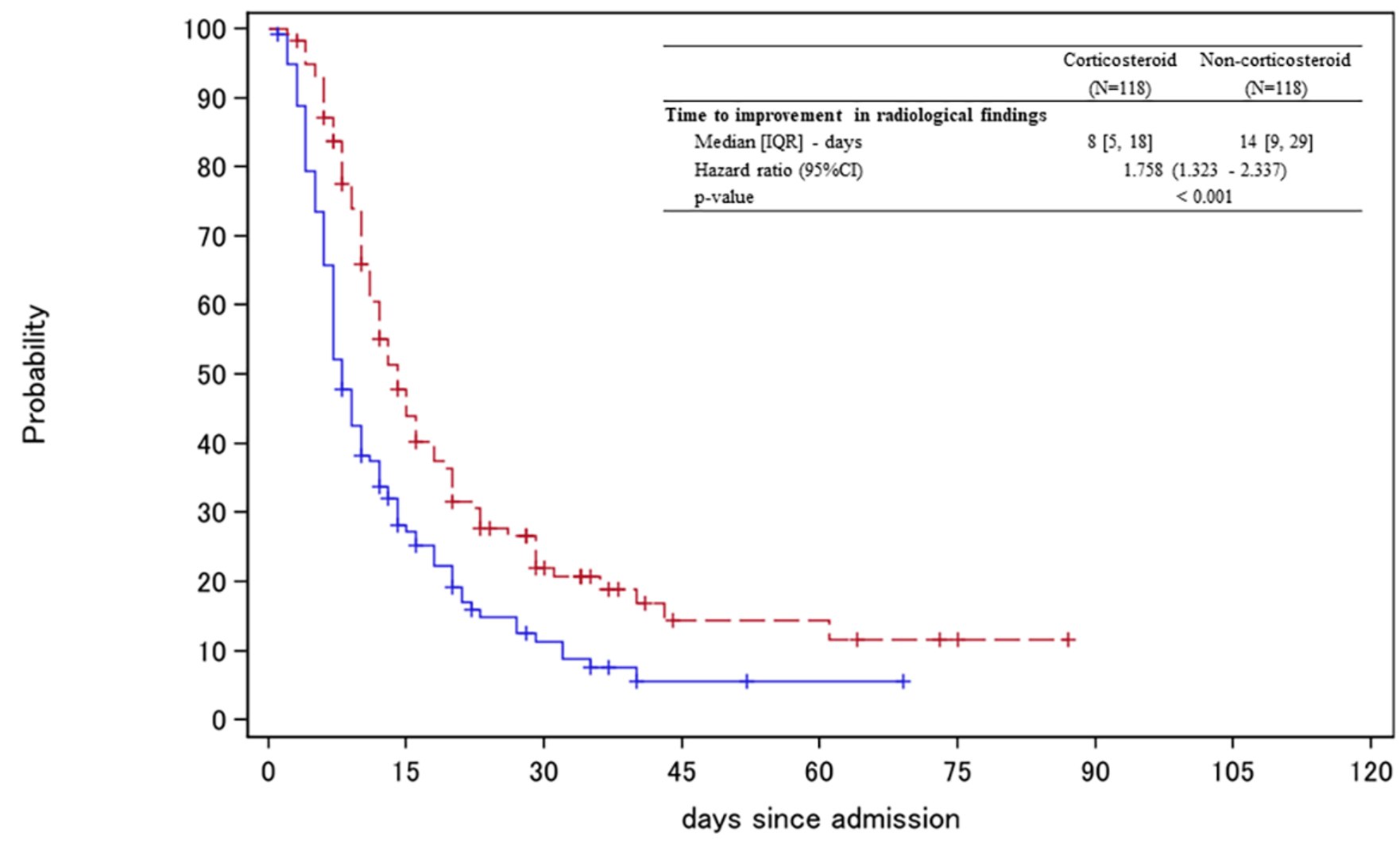

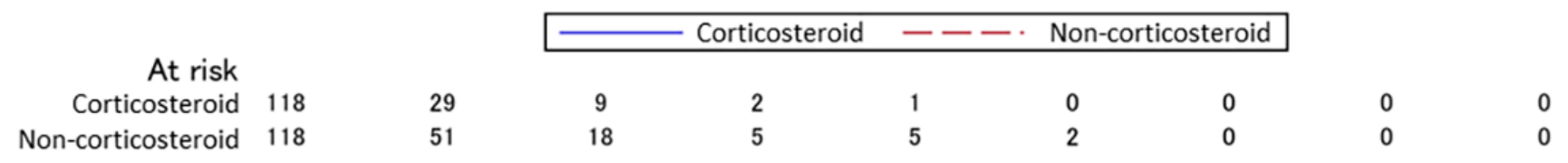

\section{Figure 3}

Time to Improvement in Radiological Findings Kaplan-Meier curves for the time to improvement in radiological findings. Cox proportional hazards model was used to calculate the hazard ratio and its $95 \%$ confidence interval for the treatment effect between groups. IQR, interquartile ranges; $\mathrm{Cl}$, confidence interval.

(A) Corticosteroid group vs Non-corticosteroid group
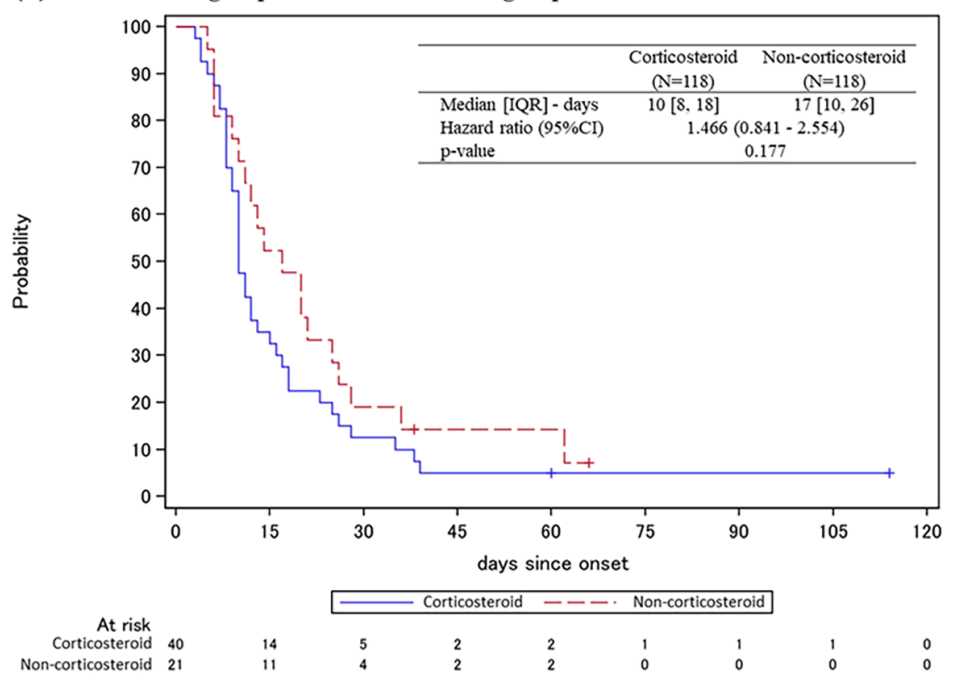

(B) Pulse/semi-pulse vs standard dosage of methylprednisolone

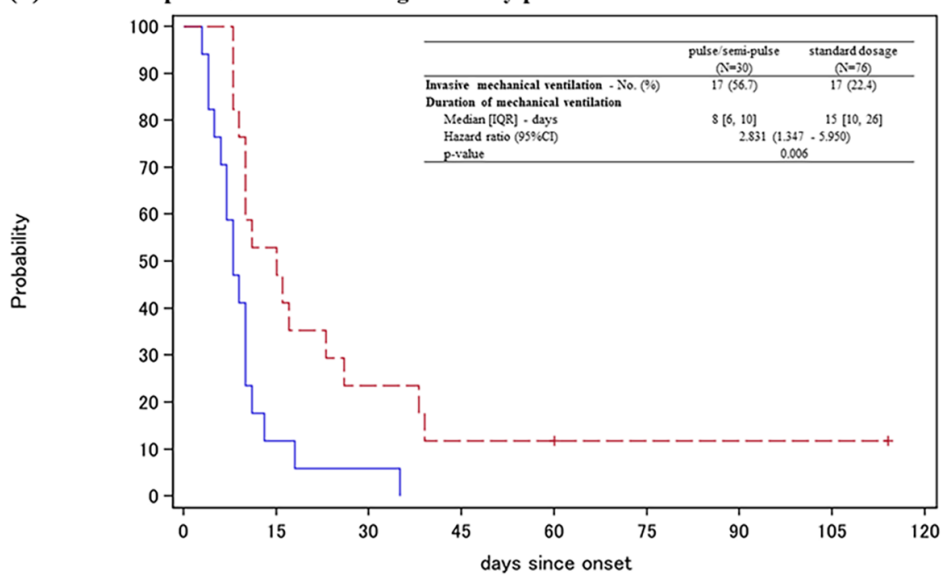

At risk At risk 17

Figure 4

Duration of Invasive Mechanical Ventilation (A) Kaplan-Meier curves for the duration of invasive mechanical ventilation comparing corticosteroid group and non-corticosteroid group. (B) Kaplan-Meier curves for the duration of invasive mechanical ventilation comparing the pulse/semi-pulse group (initial dose 
$\geq 250 \mathrm{mg} /$ day) and the standard dose group (initial dose $<250 \mathrm{mg} /$ day) among patients receiving methylprednisolone. Cox proportional hazards model was used to calculate the hazard ratio and its $95 \%$ confidence interval for the treatment effect between groups. IQR, interquartile ranges; $\mathrm{Cl}$, confidence interval.

\section{Supplementary Files}

This is a list of supplementary files associated with this preprint. Click to download.

- SupplementalMaterial.docx

- SupplFigure1.TimefromAdmissiontoTracheallntubation.tif

- SupplFigure2.SurvivalCurve.tif 